\title{
Environmentally Initiated, Self-Confirming Alienation in the Workplace
}

\author{
Laura Riolli1*, Victor Savicki² \\ ${ }^{1}$ College of Business Administration, California State University, Sacramento, USA \\ ${ }^{2}$ Western Oregon University, Monmouth, USA \\ Email: riollil@csus.edu, savickv@wou.edu
}

Received 18 June 2014; revised 20 July 2014; accepted 10 August 2014

Copyright (C) 2014 by authors and Scientific Research Publishing Inc.

This work is licensed under the Creative Commons Attribution International License (CC BY). http://creativecommons.org/licenses/by/4.0/

(c) (i) Open Access

\begin{abstract}
Employees face an increasing number of stressors that can originate from the actual performance of their duties, from the relationships with fellow workers and supervisors, and from organizational structures and expectations which accumulated over time results on burnout which contains the factor of depersonalization/cynicism. This conceptual paper focuses on an insidious pattern of behavior that evolves from chronic stress in the workplace into a pattern of ongoing behavior that increases worker alienation from others and perpetuates itself through self-confirming perceptions and actions. We argue that depersonalization/cynicism needs to be addressed at the organizational and individual level.
\end{abstract}

\section{Keywords}

\section{Alienation, Depersonalization, Cynicism, Burnout}

\section{Introduction}

Employees face panoply of stressors that can originate from the actual performance of their duties, from the relationships with fellow workers and supervisors, and from organizational structures and expectations. The current study focuses on an insidious pattern of behavior that evolves from chronic stress in the workplace into a pattern of ongoing behavior that increases worker alienation from others and perpetuates itself through selfconfirming perceptions and actions. The accumulation of chronic stress over time in the workplace that is described by the concept of burnout contains the factor of depersonalization/cynicism (Maslach \& Leiter, 1997). This factor is characterized by an emotional withdrawal and alienation from others. We will examine how depersonalization/cynicism develops, how it may be intensified, and how an employee may be both its victim and creator.

\footnotetext{
"Corresponding author.
} 


\section{Chronic vs. Acute Stress}

Stress in the workplace, as elsewhere in life, comes in two general categories: acute and chronic. The early history of psychological approaches to stress (cf. Lazarus \& Folkman, 1984) focused on acute stress. That is, stressors that were sudden, distinct, and relatively discrete episodes. Acute stressors might include death of a loved one, divorce, moving to a new city, etc. (Holmes \& Rahe, 1967). Chronic stressors, on the other hand, tend to be lower intensity, without clear beginnings and ends, and extended over longer time periods. Chronic stressors might include having a loud coworker in the next cubicle, clients who habitually show up late, computer software that freezes intermittently, etc. (Gottlieb, 1997).

Humans react to acute and chronic stressors in somewhat different ways (Kanner, Coyne, Schaefer, \& Lazarus, 1981). Acute stressors are immediately noticeable, provoke relatively intense visceral reactions, motivate people to remove the stressor or to escape the negative feelings aroused (Lazarus, 1999). From the cognitive mediational view of stress, environmental events are screened through an appraisal process that influences how intensely the stressor is perceived. If the individual appraises the stressor as a threat, he or she mobilizes to defend. If the individual appraises the stressor as indicating harm or loss, he or she mobilizes to grieve. On the other hand, if the individual appraises the stressor as a challenge, he or she mobilizes to conquer the situation, to demonstrate mastery, and to expand his or her coping repertoire (Lazarus, 1999). In the U.S. culture a premium is placed on coping skills in the face of acute stressors that are active and problem-focused; skills that directly attack the source of stress. Indirect, emotion focused coping, on the other hand, attempts to decrease the negative feelings associated with the stress while not necessarily changing the stressor. In any event, there is no doubt that a stressor exists, that it arouses emotions, and that specific action, whether direct or indirect, is taken to cope with it (Savicki \& Riolli, 2004; Riolli \& Savicki, 2010).

During chronic stress situations, reactions tend to be somewhat different. Often a low level, somewhat ambiguous stressor flies below the appraisal radar. Individuals may experience some mild irritation or annoyance, yet deem the situation too mild to react to in the way they would to a more intense, acute stressor. One approach to stressors of this type has labeled them "hassles” low level, yet powerful in provoking sympathetic nervous system responses in a manner similar to higher level acute stressors. Indeed, it may be that acute stressors gain much of their disruptive power because of multiple disturbances at the low intensity stress level (Kanner, Coyne, Schaefer, \& Lazarus, 1981). An accumulation of chronic stress is the driver for the occupational stress that has been called burnout.

\section{Burnout Factors}

Over the 40 years of research and writing about burnout that started by Freudenberger's first published use of the term "burnout" (Freudenberger, 1974), literally thousands of articles have been written about this phenomenon. Very early in the history of research on burnout, a measure of the phenomenon became adopted as the defacto standard by most researchers: the Maslach Burnout Inventory (MBI) (Maslach \& Jackson, 1976). The MBI was not a unidimensional measure of burnout, rather it had three factors. The first factor, Emotional Exhaustion, accounting for $26.4 \%$ of the variance, is characterized by feelings of being emotionally over-extended and fatigued by one's work. Second, Depersonalization, accounting for $10.9 \%$ of the variance is characterized by an unfeeling and impersonal response towards recipients of one's care or service. Third a reversed factor, Personal Accomplishment, accounting for $7.9 \%$ of the variance, is characterized as feelings of competence and successful achievement in one's work with people. In this three factor model, burnout is indicated by high levels of emotional exhaustion, high levels of depersonalization, and low levels of personal accomplishment. The advantage of the MBI's three factor model is that it gives a differentiated view of possible components of burnout. The disadvantage is that there is no one score that explains burnout, and no one threshold to be discovered that demarcates the presence of burnout from its absence. In the following sections, we will look at all three factors of burnout, with special attention to depersonalization. The alienation that develops as burnout increases that can lead to depression as well as a variety of other psychological and physical ills. A more recent rendering of the three burnout dimensions carry the labels exhaustion, cynicism, and ineffectiveness (Maslach \& Leiter, 1997). This language was adopted to expand the relevance of the burnout concept beyond the helping professions, where it was initially focused, to include non-people oriented occupations as well. For our purposes, depersonalization, aimed at clients, has the same impact as cynicism, aimed at co-workers and supervisors. Alienation from people in the workplace sews the seeds of psychological and physical health problems. 


\section{Burnout Development}

Because burnout is caused by an accumulation of low level, chronic stressors, its course is often unnoticed until a relatively high level of disturbance has occurred; its development can be insidious. Although there are multiple configurations of burnout that are impacted by multiple environmental and individual conditions, the following scenario captures the general findings from the field (Schaufeli, Maslach, \& Marek, 1993).

An initial phase of burnout development emerges from a work environment that is characterized by overwork and lack of control over workplace events (Savicki \& Riolli, 2012). These features of the work environment tax the individual's ability to maintain an empathic connection with clients and co-workers. The focus becomes getting the tasks done. Emotional connections with clients and co-workers fade into the background. This emphasis on task versus socio-emotional levels of work leads workers to feel fatigued, used up, drained. A natural response in such a situation is to protect one's self by withdrawing empathy and genuine concern for clients and co-workers. Clients become “cases" co-workers become "frenemies” whose relationships are equivocal. Workers experiencing depersonalization/cynicism pull back from others and begin to believe that only they can do the job correctly, ethically, justly, without errors. They become alienated from others, and alienate others with their assumptions that only they can define how work should be done. At the final step, job performance suffers, absenteeism and job retention suffers, and the worker's sense of work accomplishment fades. Workers feel like they are working harder but getting less accomplished (Cherniss, 1995), and that it's not their fault.

\section{Burnout Contributors}

Early, descriptive writings on burnout focused on the vulnerabilities of workers who burned out, and the literature often attributed their suffering to personal failings. However, very soon in the data driven research explorations of burnout, the environment, specifically the work environment, was found to be a dramatically more potent source of burnout. It is environmental factors that we enumerate in this section. Only major themes will be sketched here since an extensive review of research findings is beyond the scope of this article.

\subsection{Meta-Analysis}

Lee and Ashforth's (Lee \& Ashforth, 1996) meta-analysis of correlates to the Emotional Exhaustion, Depersonalization and Personal Accomplishment summarizes results from 61 of 77 research-based studies done with the Maslach Burnout Inventory from 1982 to 1994. Lee and Ashforth (1996) categorized variables which correlated with burnout into the broad categories of Demands and Resources. Demands included job stressors such as Workload, and Role Conflict. Resources included a variety of environmental features such as Social Support, Job Enhancement Opportunities, and Reinforcement Contingencies. Several job stressors were related to both Emotional Exhaustion and Depersonalization: higher Role Ambiguity, Role Conflict, Role Stress, Number of Stressful Events, Workload, Work Pressure and lower Role Clarity. For Resources, strong relationships with Emotional Exhaustion and Depersonalization were found with lower number of Work Friends, Skill Utilization and higher Unmet Expectations. The authors speculated that in relation to Emotional Exhaustion and Depersonalization workers were especially sensitive to work demands and might perceive that more energy should be expended to reduce stress demands than to enhance resources. For Personal Accomplishment there was a weaker relationship with both Demand and Resource variables. On the Demand side higher Stressful Events was most strongly related to higher Personal Accomplishment. On the Resource side, more Work Friends, and greater Participation related strongest to Personal Accomplishment. The pattern of correlations indicates that Personal Accomplishment is a qualitatively different job-related affective response than the other two burnout dimensions. Access to support from co-workers and supervisors proved to be beneficial, while lower levels of these environmental factors contributed to burnout. Alienation was both the result and the cause of some aspects of burnout.

Personal coping styles were differentially related to burnout. Lower Preventive coping was related to Depersonalization; while higher problem focused coping was related to Personal Accomplishment. Related research indicates that Escape coping is also related to higher levels of Emotional Exhaustion and Depersonalization (Koeske, Kirk, \& Koeske, 1993; Riolli \& Savicki, 2006).

\subsection{Maslach and Leiter's Integration}

Maslach and Leiter (1997) made several integrative comments concerning burnout and its precursors. First, they 
promoted the idea that burnout dimensions should be viewed as potentially bipolar. Opposite ends of the bipolar continua could be described as not merely the absence of burnout, but rather the presence of psychological well-being at work. Emotional Exhaustion was contrasted with higher levels of physical and psychological energy. Depersonalization or cynicism was contrasted with involvement and commitment to one's job. Diminished Personal Accomplishment in the form of perceived and actual ineffectiveness on the job was contrasted with a heightened sense of job self-efficacy. As they advocated: "burnout is not just about the presence of negative emotions, also about the absence of positive ones” (p. 28).

Emphasis on organizational or situational precursors to burnout focused on mismatches between individual worker capacities and needs in comparison to organizational structures and demands. Maslach and Leiter (1997) espoused the position that organizations not individual workers are most responsible for chronic situations that foment burnout, and that emphasis on individual worker responses can undermine real solutions to burnout. "As far as the organization is concerned, when burnout is seen to be a personal experience... it becomes a personnel problem rather than a strategic management problem” (pp. 33-34). Thus they discuss six areas of organizational structure and design that can create mismatches between the individual workers and their work situation: work overload, lack of control, insufficient reward, unfairness, breakdown of community, and value conflicts. Once again the emphasis is on diminished resources rather than work demands (work overload) when this is placed within the framework of the demands versus resources categorization of Lee and Ashforth (1996).

\section{Cultural Impact on Burnout}

Savicki (2002) explored the relationship of burnout to dimensions of culture across 13 different cultures. The dimensions used to describe these cultures originated from Hofstede's work (Hofstede, 2001) which uses four descriptors to differentiate cultures: Individualism vs. Collectivism, Power Distance, Uncertainty Avoidance, and Masculinity (Career Sucess) vs. Femininity (Quality of Life). The general hypothesis of this research was that cultural differences would lead to differences in burnout.

For example, in Denmark, Scotland, and Israel, Individualism and low Uncertainty Avoidance made it possible for individual workers to take more independent action within a context that did not hinder them through excessive rules and regulations. With a cultural value focused on achievement at work, this combination has allowed the cultures to provide different kinds of support for workers that may help them maintain lower burnout. By and large, work structures are malleable, not written in stone; recognition is available for satisfactory individual performance; and the development of the individual as a resource for the organization is accepted.

In contrast, in Germany and Austria, individualism combines with high Uncertainty Avoidance in the context of emphasis on career achievement. A cultural value of avoiding ambiguity and uncertainty at work takes the form of formality and a plethora of rules and regulations that attempt to anticipate all variations. These rules, once in place, are often not re-evaluated as circumstances change, but rather are seen as having importance in and of themselves. Sometimes, outdated or even conflicting regulations contribute more stress to the situation rather than avoiding it. Workers who value individual responsibility can get caught in this tangle of regulations. They may deem it more important to satisfy the rules than to respond to the uniqueness of the situation. Not following the rules can increase anxiety, and following the rules may lead to unsatisfactory outcomes: a real double bind.

In complete contrast is the Slovak Republic with low Uncertainty Avoidance is combined with Collectivism and Quality of Life. Even though the position of Slovakia contrasts totally with that of Germany and Austria, the outcome is also high burnout. In this case, however, burnout is heavily loaded with low Personal Accomplishment. That is, Slovak workers generally showed a very low sense of achievement at work. Low salaries, centralized management structures, and lack of career options combined to make many Slovak workers feel trapped in their positions. The absence of Individualism as a cultural value also made it more difficult for workers to press for better circumstances or to seek other jobs.

For the U.S., a somewhat confusing configuration of burnout factors is supported by various cultural work value dimensions. Savicki (2002) found that U.S. workers in the child and youth care field showed high emotional exhaustion, high depersonalization and high personal accomplishment. Two of the three MBI factors are consistent with burnout, while the other is not. One interpretation of the configuration of burnout factors in the U.S. is that workers act as if they must be working overly hard and suffering for it in order to feel like they are doing a good job. Accomplishment at work is supported by being overworked, feeling buffeted by chaotic work 
demands, and lacking a sense of autonomy. Across the globe, U.S. citizens have the reputation for being "busy.” In industrialized nations, U.S. workers are least likely to take their vacations, and vacation time is quite brief in comparison with other countries, especially those in Europe. It is the combination of the cultural work dimensions of Individualism and Career Success that seem to most influence burnout in the U.S.

As Savicki (2002) says, “Career Success served as if it were a catalyst to activate the impact of Individualism” (p. 169).

It appears that the two cultural work values operate in concert. When career advancement and identity are important in a culture, then a culture that also advocates individual action and responsibility is more likely to spawn emotional fatigue. This result is consistent with the cognitive-mediation model of stress (Lazarus, 1999) which states that important goals (e.g. success at work) have the power to alter perceptions of stress. The framing of individual blame for important work distresses is felt more intensely when work is the major source of self-esteem (p. 169).

\section{Self-Perpetuating Cycles of Burnout}

Once an individual is caught in the symptomatic stages of burnout, there may be patterns of behavior that make it more difficult for him or her to escape. Kanner et al. (1981) point to a situation in which symptoms of chronic stress (hassles) may be involved in perpetuating further hassles; "being symptomatic may lead to increased hassles" (p. 21). For example, workers begin to feel like only they are working hard. After all, they are exhausted. They take comfort in their high values for quality of work; adhering to those values, in their perception, is one of the things that make work so difficult. Additionally, it seems like co-workers are not working as hard, and not working up to the standards set by the burning out worker. A common type of aphorism voiced by such workers is "If you want something done right, you will have to do it yourself." Of course, following this aphorism only adds to exhaustion. Workers are working harder and enjoying it less and less.

At the same time, burning out workers feel alienated at work. The clients they serve seem not to appreciate the worker's efforts; co-workers seem to resent the workers rigid behavior; supervisors seem glad to assign more tasks, but do not acknowledge the worker's efforts in a way that is satisfying for the worker. The burning out worker can easily make the fundamental attribution error (Ross, 1977) which assigns errors or sub-standard work behavior of others to their internal traits or states. Others at work become seen as lazy, deceitful, irritating, and uncommitted. In consequence of perceptions such as these, the worker draws further away from others at work; feels more isolated and burdened; dreads interaction with people at work. Such isolation and alienation sets the stage for more intense symptoms such as depression.

Concomitantly, the worker's performance is likely to suffer. He or she is more likely to miss work because of illness, certainly, engagement and satisfaction with work decreases. One would think that a worker experiencing these symptoms would seek to change their circumstances. However, there are several factors that encourage burning out workers to stay "stuck" in their unhealthy situation. First, given their alienation from others at work, and possibly a cultural work value of individualism, it is exceedingly difficult for them to ask for help. They feel like they "should" be able to cope at work. After all, in the classic case, the chronic build-up of burnout is not marked by major trauma, rather it is a slow progression of barely noticeable stressors, each one of which is annoying yet manageable on its own. Burnout has been called an "emotional repetitive strain injury" (Savicki, 2002).

Secondly, the burning out worker is committed to values of service and high performance. In a situation in which he or she sees work performance of self and others fall below those values, the solution is to try harder. There is virtue in upholding one's values in the face of tribulation and uncommitted clients, co-workers, and supervisors. Virtuous behavior is a reward in itself; though that reward increasingly is offset by symptoms that develop as a result of exhaustion, cynicism, and decreasing feelings of work efficacy. Burning out workers can believe that changing their work behaviors is akin to abandoning closely held, identity defining values. An early view of burnout focused on the disillusionment that burned out workers reported. They began their careers with idealism and excitement, only to have those characteristics crushed by the realities of work (Cherniss, 1995).

Third, the concept of the "wounded healer" has some influence, particularly in the helping professions (Miller \& Baldwin, 1987). A version of this concept also applies to non-service jobs. The idea here is that workers who have undergone problems in their lives may be more effective by virtue of the perspective that their unpleasant 
experience gives them. Unfortunately, embedded in this concept, for some, is the idea that in order to be effective, one must suffer either in the past or present. Obviously, not all workers share this point of view. But it is a comforting idea for burning out workers casting about for a reason for their discomfort. In this framework, the symptoms the burning out worker experiences are signs that he or she is virtuous. Such workers carry on despite personal anguish and pain. Their distress is an indicator that they must be doing the right things because it hurts.

Finally, conditions external to the work environment may lock a worker into an unhealthy situation. Sometimes, economic conditions are such that leaving one's current job is not realistic. Other positions are few and pay and benefits substantially less. Some Correctional Officers can feel stuck in long term jobs that produce high levels of alienation and detachment because the State funded jobs they hold pay more and have higher benefits than anything they could find in the private sector. For many of them, putting in their time at work is the least rewarding aspect of their lives, yet they see no reasonable alternative (Savicki, Cooley, \& Gjesvold, 2003).

\section{Implications for Prevention and Intervention}

Burnout, as a phenomenon, is problematic in and of itself. When paired with the self-perpetuating pattern described above, it can be devastating to individual workers, and crippling to their organizations. The literature offers ideas about prevention and intervention.

Mirvis and Kanter (1989) identify that employment content such as working conditions, work groups and pay practices, is the best predictor of work attitudes and subject of praise or criticism. It is suggested that organizations must address this increasing cynicism by managing more fairly, and operating in an open, honest, straightforward, and particularly, realistic manner (Mirvis \& Kanter 1989; Riolli \& Savicki, 2006). Employees can participate in governance, provide regular reality checks to management, have positive role models, and perceive an open and honest pay system.

It is important to give employees something to believe in. Using corporate mission and values statement can be very useful, but the major focus should be on the fact that they are widely distributed, and consistently implemented.

In their article Regoli, Crank and Culbertson (1989) found that in a group of police chiefs, increasing a sense of professionalism reduced cynicism and work alienation. Regoli, Poole and Lotz (1981) found that generally only one professional dimension-a sense of calling — reduced prison guard's cynicism. They suggested that prisons work overall to try to make work an end in itself. Another study when investigating police cynicism, job satisfaction, and work relations of police chiefs in departments of different sizes, as result of less direct communications, control and clarity of directions, the study concluded that larger organizations were more likely to have more cynical police chiefs, due to the less direct communications (Regoli, Crank, \& Culbertson, 1989). Although these studies in prison and police offer some good insights their outcomes should be applied with caution in other industries since these organizations have different cultures, systems and structures.

The loneliness, depression, and cynicism experienced by workers can also by exacerbated by pluralistic ignorance. That is, workers caught in the self-perpetuating cycle of depersonalization and cynicism may come to believe that they are the only ones suffering in this manner, while others in the organization may also unwittingly share this experience. Each can be unaware that their experience is not isolated but relatively common; each can cut off possible support by virtue of seeing themselves as unique (Halbesleben, Wheeler, \& Buckley, 2007). Organizations can help such workers by raising the issue of cynicism as a concern in a nonjudgmental manner.

In recent years the bipolar conception of burnout has received attention in workplace research: burnout vs. engagement. It can be argued that both these concepts have embraced the concept of alienation. Work engagement is measured on three dimensions: Vigor-feelings of energy, persistence, and resilience; Dedication-feelings of high work involvement, motivation, and inspiration; and, Absorption-feelings of immersion in and strong attachment to work (Maslach et al., 2001: p. 417). Both burnout and disengagement focus primarily on work and organizational factors external to the individual as the source and focus of the feelings experienced by the individual in relation to their work. As result one can argue that neither burnout nor disengagement effectively capture self-estrangement resulting from factors internal to the individual. The perpetuation of depersonalization and cynicism may be also stem from factors internal to an individual. This conceptualization can offer better ways in which management might increase attempts to ameliorate feeling of indifference and detachment and their impact on the workplace. It is also important that management recognizes the importance of factors internal 
to the individual. The key to understanding the problem in particular in managing alienation relies on recognizing the relationship between the individual and the organization.

\section{Future Research}

Naturally limitations are associated with this conceptual framework. There should be data collection in different kind of organizations and different cultures that may shed light on causes and consequences of depersonalization and cynicism and ways to manage it in real organizations. Research should explore the effects of other factors such as gender on of depersonalization and cynicism. Future research should explore whether or not the effects of the above mentioned variables vary according to country or other culture specific factors that may or may not influence feelings of depersonalization and cynicism. In addition, there should be longitudinal research carried out to investigate the change in depersonalization and cynicism after changing organizational systems and processes.

\section{Conclusion}

The growing research interest in the significance of mental health in the workplace has called the organizations to take a more anticipatory role in changing work environments and systems to make the workplace more safe for good mental health. In this paper we present a conceptual perspective on how organizations might take proactive steps to revisit the concept of "alienation" and its consequences.

We believe that the key to managing the problems associated with alienation lies in organizations' recognizing that this problem needs to be addressed at two levels: at the organizational level in terms of factors external to the individual such as work and organizational systems and processes, and in terms of internal individual factors such as employee state of mind.

\section{References}

Cherniss, C. (1995). Beyond Burnout: Helping Teachers, Nurses, Therapists \& Lawyers Recover from Stress \& Disillusionment. New York, NY: Routledge.

Freudenberger, H. J. (1974). The Staff Burnout Syndrome in Alternative Institutions. Psychotherapy: Theory, Research and Practice, 12, 73-82. http://dx.doi.org/10.1037/h0086411

Gottlieb, B. H. (Ed.), (1997). Coping with Chronic Stress. New York, NY: Plenum Press. http://dx.doi.org/10.1007/978-1-4757-9862-3

Halbesleben, J. R. B., Wheeler, A. R., \& Buckley, M. R. (2007). Understanding Pluralistic Ignorance in Organizations: Application and Theory. Journal of Managerial Psychology, 22, 65-83. http://dx.doi.org/10.1007/978-1-4757-9862-3

Hofstede, G. H. (2001). Culture’s Consequences: Comparing Values, Behaviors, Institutions, and Organizations across Nations. Thousand Oaks, CA: Sage Publications.

Holmes, T. H., \& Rahe, R.H. (1967). The Social Readjustment Rating Scale. Journal of Psychosomatic Research, 11, 213-221. http://dx.doi.org/10.1016/0022-3999(67)90010-4

Kanner, A. D., Coyne, J. C., Schaefer, C., \& Lazarus, R. S. (1981). Comparison of Two Modes of Stress Measurement: Daily Hassles and Uplifts versus Major Life Events. Journal of Behavioral Medicine, 4, 1-39. http://dx.doi.org/10.1016/0022-3999(67)90010-4

Koeske, G. F., Kirk, S. A., \& Koeske, R. D. (1993). Coping with Job Stress: Which Strategies Work best? Journal of Occupational \& Organizational Psychology, 66, 319-335. http://dx.doi.org/10.1016/0022-3999(67)90010-4

Lazarus, R. S. (1999). Stress and Emotion: A New Synthesis. New York, NY: Springer Publishing.

Lazarus, R. S., \& Folkman, S. (1984). Stress, Appraisal, and Coping. New York, NY: Springer.

Lee, R. T., \& Ashforth, B. E. (1996). A Meta-Analytic Examination of the Correlates of the Three Dimensions of Job Burnout. Journal of Applied Psychology, 81, 123-133. http://dx.doi.org/10.1037/0021-9010.81.2.123

Maslach, C., \& Jackson, S. E. (1976). The Maslach Burnout Inventory. Palo Alto, CA: Consulting Psychologists Press.

Maslach, C., \& Leiter, M. P. (1997). The Truth about Burnout: How Organizations Cause Personal Stress and What to do about It. San Francisco, CA: Jossey-Bass.

Maslach, C., Schaufeli, W. B., \& Leitner, M. P. (2001). Job Burnout. Annual Review of Psychology, 52, 397-422. http://dx.doi.org/10.1146/annurev.psych.52.1.397

Miller, G. D., \& Baldwin, D. C. (1987). Implications of the Wounded Healer Paradigm for the Use of the Self in Therapy. 
Journal of Psychotherapy and the Family, 3, 139-151. http://dx.doi.org/10.1300/J287v03n01_13

Mirvis, P., \& Kanter, D. L. (1989). Combating Cynicism in the Workplace. National Productivity Review, 8, 377-394. http://dx.doi.org/10.1002/npr.4040080406

Regoli, R., Poole, E. D., \& Lotz, R. (1981). An Empirical Assessment of the Effect of Professionalism on Cynicism among Prison Guards. Sociological Spectrum, 1, 53-65. http://dx.doi.org/10.1080/02732173.1981.9981618

Regoli, R. M., Crank, J. P., \& Culbertson, R. G. (1989). Police Cynicism, Job Satisfaction, and Work Relations of Police Chiefs: An Assessment of the Influence of Department Size. Sociological Focus, 22, 161-171. http://dx.doi.org/10.1080/00380237.1989.10570540

Riolli, L., \& Savicki, V. (2006). Impact of Fairness, Leadership, and Coping on Strain, Burnout, and Turnover in Organizational Change. International Journal of Stress Management, 13, 351-377. http://dx.doi.org/10.1037/1072-5245.13.3.351

Riolli, L., Savicki, V., \& Spain, E. (2010). Positive Emotions in Traumatic Conditions: Mediation of Appraisal and Mood for Military Personnel. Military Psychology, 22, 176-206. http://dx.doi.org/10.1080/08995601003638975

Ross, L. (1977). The Intuitive Psychologist and His Shortcomings: Distortions in the Attribution Process. In L. Berkowitz (Ed.), Advances in Experimental Social Psychology (pp. 173-220). New York: Academic Press.

Savicki, V. (2002). Burnout across Thirteen Cultures: Stress, and Coping in Child and Youth Care Workers. Westport, CT: Praeger.

Savicki, V., Cooley, E. J., \& Gjesvold, J. (2003). Harassment as a Predictor of Job Burnout in Correctional Officers. Criminal Justice and Behavior, 30, 602-619. http://dx.doi.org/10.1177/0093854803254494

Savicki, V., \& Riolli, L. (2004). Optimism and Coping: Resilience under Three Types of Stress. Western Psychological Association Conference, Phoenix.

Savicki, V., \& Riolli, L. (2012). Organizational Change and Perceptions of Work and Justice. 92nd Annual Meeting of the Western Psychological Association, San Francisco.

Schaufeli, W. B., Maslach, C., \& Marek, T. (Eds.) (1993). Professional Burnout: Recent Developments in Theory and Research. Washington DC: Taylor and Francis. 
Scientific Research Publishing (SCIRP) is one of the largest Open Access journal publishers. It is currently publishing more than 200 open access, online, peer-reviewed journals covering a wide range of academic disciplines. SCIRP serves the worldwide academic communities and contributes to the progress and application of science with its publication.

Other selected journals from SCIRP are listed as below. Submit your manuscript to us via either submit@scirp.org or Online Submission Portal.
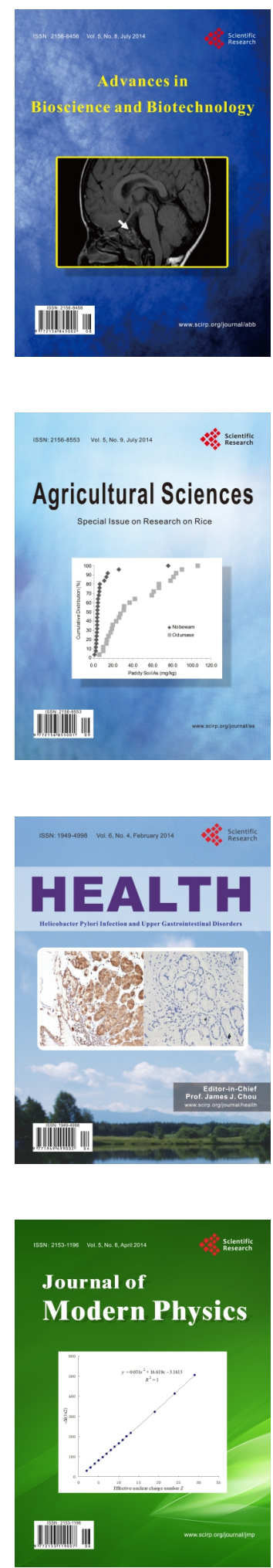
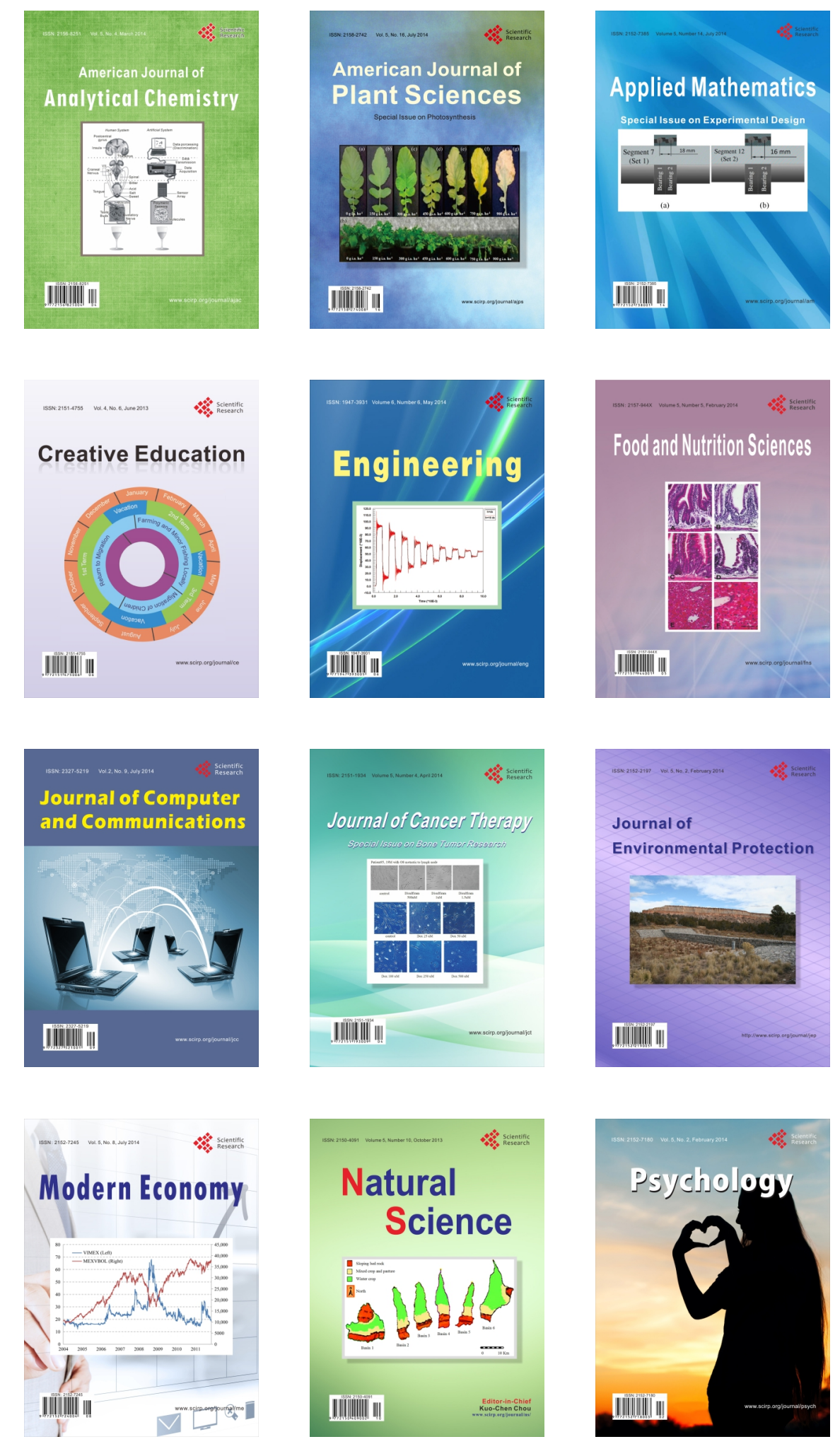